\title{
Medida socioeducativa e a inserção da Lei simbólica: uma experiência
}

Educational measure and insertion of symbolic Law: an experience

Medida socioeducativa y la inserción de la Ley simbólica: una experiencia

\author{
Roseane Torres Madeiro* \\ Roseane Freitas Nicolau*
}

\begin{abstract}
Resumo
Este artigo pretende discutir a possibilidade de uma medida socioeducativa (aplicada em uma instituição jurídica) alcançar um adolescente infrator no sentido da responsabilidade por seu ato infracional. Parte-se de uma experiência com adolescentes que cometeram atos infracionais ocorrida no Centro de Internação do Adolescente Masculino (CIAM), responsável por aplicar a medida socioeducativa de internação provisória, no Estado do Pará. Aposta-se em que o alcance de uma medida socioeducativa se dá em nível do campo simbólico, em que, no tratamento com o adolescente infrator, seja visada não somente a uma reinserção social, mas igualmente um assentimento à ordem simbólica.
\end{abstract}

Palavras-chave: Medida socioeducativa. Lei simbólica. Ato infracional. Adolescência.

\begin{abstract}
This article discusses the possibility of an educational measure (applied in a legal institution) achieving an adolescent offenders awareness to a sense of responsibility for his offense. This is based on an experience with adolescents who have committed illegal acts occurred Center Inpatient Adolescent Male (CIAM), responsible for implementing the educational measure of Provisional Admission in Pará gambled that the range of an educational measure is given to the level of the symbolic field, where the treatment with the adolescent offender, is aimed not only at social reintegration, but also a leaning to the symbolic order.
\end{abstract}

Keywords: Educational measure. Symbolic law. Act infraction. Adolescense.

\footnotetext{
Texto recebido em janeiro 2013 e aprovado para publicação em novembro de 2013.

Mestra em Psicologia pela Universidade Federal do Pará (UFPA), professora do Curso de Psicologia da Escola Superior da Amazônia (Esamaz), psicóloga.E-mail: rose_madeiro@yahoo.com.br.

* Professora da Faculdade de Psicologia e do Programa de Pós-Graduação em Psicologia da Universidade Federal do Pará, psicanalista, membro do GT Dispositivos Clínicos em Saúde Mental da ANPEPP, membro da Escola Letra Freudiana. E-mail:rfnicolau@uol.com.br.
} 


\section{Resumen}

En este artículo se discute la posibilidad de que una medida socioeducativa (aplicada en una institución jurídica) afecte a un adolescente infractor en la responsabilidad por su delito. Se basa en una experiencia con adolescentes que han cometido actos infraccionales que ocurrió en el Centro de Internación del Adolescente Masculino (CIAM), responsable de la aplicación de la medida socioeducativa de internación provisional en el Estado de Pará. Se apuesta en que el alcance de una medida socioeducativa se dé en el nivel del campo simbólico, donde el tratamiento con el adolescente infractor está dirigido no sólo a la reinserción social, sino también al asentimiento del orden simbólica.

Palabras clave: Medida socioeducativa. Ley simbólica. Acto infraccional. Adolescencia.

0 atual modelo de atendimento ao adolescente envolvido em atos infracionais é norteado pelo Estatuto da Criança e do Adolescente ("Lei n. 8.069, 1990"), que estabelece uma doutrina de proteção integral, voltada para a garantia de todos os seus direitos. Entretanto, embora vise, com suas ações, a promover a inclusão social, o desenvolvimento saudável e a recuperação do adolescente, tal política tem fracassado no seu objetivo de "ressocialização" e readaptação social, tornando frequente a reincidência do ato transgressor.

Neste artigo, refletimos sobre as medidas socioeducativas aplicadas de forma estéril em um determinado contexto, visando a discutir a possibilidade de, em uma instituição jurídica, haver uma escuta que faça surgir o sujeito implicado nas suas ações para que possa ser responsabilizado por elas. Nossa experiência com adolescentes que cometeram atos infracionais ocorreu no Centro de Internação do Adolescente Masculino (CIAM), responsável por aplicar a medida socioeducativa de internação provisória no Estado do Pará.

Nesse contexto, a escuta de adolescentes entre 13 a 17 anos que cometeram atos infracionais, tais como homicídios, roubos, furtos, estupros, sequestros e tráfico de entorpecentes, forjou muitos questionamentos relativos a um sistema que se pretende reeducativo, mas que fracassa na aplicação da medida socioeducativa. O que estaria na origem desses fracassos? Por que, apesar do esforço dos profissionais envolvidos na recuperação, os adolescentes voltam a cometer atos infracionais? O que manteria essa repetição? Haveria na aplicação da medida um descompasso que impede a lei jurídica de ser cumprida? Como se coloca essa questão para cada sujeito e no que isso pode estar implicado 
com o sucesso ou fracasso da medida?

Essas são algumas das questões que nos motivaram a escrever este texto, no qual pretendemos, no diálogo com o Direito, confrontar a maneira como é aplicada a medida socioeducativa no contexto do CIAM com o que nos ensina a psicanálise de Freud e Lacan relativamente à internalização da Lei simbólica, esta que permite ao sujeito regular seus atos e se responsabilizar por eles. Destacamos aqui a diferença e a relação de interdependência que a psicanálise aponta entre a Lei e as leis. A Lei, com maiúscula, refere-se à Lei do Pai, que dá ao sujeito sua condição de assujeitado à ordem simbólica e que decorre do complexo de Édipo, instaurador da interdição do incesto. As leis são aquelas estabelecidas legalmente como normas para regular o funcionamento de uma sociedade e se acham em uma relação de dependência com a Lei, considerando que, sem esta, o sujeito não entra nas leis. Nesse sentido, a Lei sobre a qual a psicanálise se apoia está referida ao complexo de Édipo, este que institui a Lei do Pai estabelecendo a barreira contra o incesto e o parricídio, cuja função simbólica é universal. Essa operação estrutura o ordenamento psíquico dos indivíduos ante o imperativo da constituição sexual e permite a filiação que vem assegurar para cada um a sua identidade. Portanto o incesto e o parricídio são as bases de todas as proibiçôes culturais, com a Lei fundando não só a estrutura psíquica do sujeito, mas também as condiçôes para que este ocupe um lugar social e para que o ordenamento jurídico alcance valor de autoridade.

O que observamos no CIAM é que a lei jurídica é aplicada sem levar em conta como se coloca para cada um a sua relação com a Lei, esta que permite a responsabilidade individual por seu ato, seja este legal ou ilegal. Sem a inscrição da Lei, o cumprimento da lei jurídica pode até ocorrer, mas como puro legalismo, obediência cega ou assujeitamento, sem a responsabilidade pelo ato. Não basta então obedecer à lei para estar em regra com a questão da responsabilidade. É necessária a implicação do sujeito com suas açôes para que ele possa se responsabilizar por elas.

Partimos da ideia de que isso só é possível apostando-se na escuta do um a um nas instituições encarregadas de aplicar as medidas socioeducativas, pois esta é a via que permite articular uma resposta subjetiva que possa implicar o sujeito. O que a psicanálise propõe para reger as ações do sujeito é o desejo, cuja falta é estrutural, constituinte e faz objeção a qualquer tipo de universalidade, pois é o que o sujeito tem de mais particular. Assim, escutar a posição do sujeito em relação ao seu desejo no ato infracional pode fazer surgir a possibilidade de o adolescente se responsabilizar pela singularidade do seu desejo (Lacan, 2008a). 
Acreditamos que o psicanalista, mesmo em uma instituição onde predomina o discurso corretivo e repressivo, pode tomar o saber inconsciente como vetor possível de mudança de posição do sujeito frente ao seu ato e possibilitar o fortalecimento de seus laços sociais. Para tanto, coloca-se a questão da responsabilidade, que implica a inscrição na Lei e que esta seja operante para o sujeito, conforme vimos acima. Sublinhamos, no entanto, que obedecer ou transgredir a lei não implica que o sujeito esteja ou não marcado pela Lei do Pai, e que não é a adaptação às leis sociais que indicam tal marca. É preciso escutar como se instaura a relação da Lei e das leis para esses adolescentes, para que possam ou não se responsabilizar por seu desejo. Com isso, podemos dizer que um adolescente que comete um crime, embora esteja fora da norma ou na ilegalidade, pode perfeitamente estar assujeitado à Lei. $\mathrm{O}$ trabalho com esses adolescentes deve considerar a possibilidade de que estes possam estabelecer uma relação entre Lei e leis, em que a escolha forçada no campo da ilegalidade ou do crime não seja a única forma de assumir seu desejo.

Como harmonizar isso com uma política do universal, do bem para todos? A experiência analítica não é orientada por valores ideais, em que haveria um "bem" a ser atingido. O processo analítico é dirigido por pressupostos que não se aplicam a não ser no um a um, a partir de uma escuta. Vejamos como articular isso no espaço institucional encarregado de aplicar a lei jurídica, estabelecendo normas.

\section{A psicanálise e o campo jurídico}

O Centro de Internação do Adolescente Masculino (CIAM), instituição pública do âmbito jurídico e social, é uma das unidades da Fundação de Atendimento Socioeducativo do Pará (Fasepa). ${ }^{1}$ A internação provisória aplicada como uma das medidas socioeducativas visa a recuperar o adolescente infrator e se constitui em um ato que, ao mesmo tempo, cerceia a liberdade e se encarrega de normatizar e adaptar aquele que age contra a lei jurídica. A medida estabelecida pelo Estatuto da Criança e do Adolescente (“Lei n. 8.069, 1990") é aplicada pelo discurso jurídico visando à reinserção social.

A Fasepa dispõe de estabelecimentos nomeados unidades de atendimento socioeducativo espalhados pela Região Metropolitana de Belém, bem como em cidades do interior. O CIAM, assim como as demais unidades da Fasepa, está ligado diretamente ao Juizado da Infância e Juventude de Belém, porém

\footnotetext{
Antiga Fundação da Criança e do Adolescente do Pará (Funcap) sofreu mudança de nome em 2011. Criada em 1967, é o órgão responsável pela coordenação e execução do atendimento socioeducativo de adolescentes em conflito com a lei, bem como de seus familiares, a partir da doutrina de proteção integral e desenvolvimento social.
} 
atende às comarcas de todo o Estado do Pará.

Todas as unidades da Fasepa têm o objetivo de reinserir em seu meio familiar e comunitário o adolescente em conflito com a lei, bem como seu aprimoramento educacional e profissional, por meio de medida socioeducativa que é entendida como "a manifestação do Estado, em resposta ao ato infracional, praticado por menores de 18 anos, de natureza impositiva, sancionatória e retributiva, cuja aplicação objetiva inibir a reincidência, desenvolvida com a finalidade pedagógico-educativa" (Liberati, 2002, p. 101). São elas: advertência, obrigação de reparar o dano, prestação de serviços à comunidade, liberdade assistida, inserção e regime de semiliberdade e internação em estabelecimento educacional ("Lei n. 8.069, 1990").

No caso do CIAM, a medida protetiva em vigor é a internação provisória. Após o momento do ato infracional, feito o boletim de ocorrência na Divisão de Atendimento ao Adolescente (Data), o adolescente é encaminhado inicialmente ao CIAM, onde passará 42 dias, no transcorrer dos quais receberá atendimento psicossocial e pedagógico, enquanto seu processo é encaminhado pelos órgãos jurídicos responsáveis. Ao final desse prazo, deve ser realizada uma audiência com o juiz responsável pelo Juizado da Infância e Juventude, em que será sentenciada a medida socioeducativa. Daí em diante, o adolescente é encaminhado do CIAM para alguma outra unidade da Fasepa, para cumprir a medida estabelecida, ou conduzido ao convívio familiar, caso seja sentenciado por medida socioeducativa em meio aberto.

Durante o período de internação provisória, o adolescente segue uma rígida rotina estabelecida pela instituição, tal como horário para as refeições, para as atividades pedagógicas, para os atendimentos com a equipe técnica, para as atividades esportivas e de saúde, bem como para receber visita dos familiares.

Com tal rotina "normativa", a instituição visa a estabelecer normas e regras que ordenem o dia a dia desses adolescentes. De fato, a maneira como isso é apresentado segue os moldes do sistema penitenciário, em que prevalece a repressão, a intimidação e a violência, em detrimento das ações socioeducativas. Apesar dos esforços dos diversos profissionais envolvidos no atendimento ao adolescente (psicólogos, assistentes sociais, pedagogos e educadores) em fazer cumprir o estabelecido, é frequente a desobediência e a transgressão das normas. O que isso quer dizer?

Consideramos que essa recusa aponta para processos psíquicos subjacentes oriundos de conflitos entre normas, lei jurídica e Lei simbólica. 
Vemos aí que não se trata apenas de aplicar ou obedecer à lei jurídica, mas da posição do sujeito frente à Lei, única possibilidade de elevar seu ato à categoria da responsabilidade e da verdade do sujeito. Mas que responsabilidade para o adolescente diante da lei jurídica?

\section{A responsabilidade pelo ato infracional}

À luz da lei jurídica (especificamente segundo o art. 27 do Código Penal Brasileiro - CPB), os indivíduos que têm menos de 18 anos não cometem crimes, mas sim atos infracionais, uma vez que são considerados inimputáveis e, portanto, "ficam sujeitos às normas estabelecidas na legislação especial” (“Decreto-Lei n. 2.848, 1940”, p. 541).

A inimputabilidade penal é prevista no art. 26 do $\mathrm{CPB}$ :

É isento de pena o agente que, por doença mental ou desenvolvimento mental incompleto ou retardo, era, ao tempo da ação ou da omissão, inteiramente incapaz de entender o caráter ilícito do fato ou de determinar-se de acordo com esse entendimento ("Decreto-Lei n. 2.848”, 1940, p. 541).

Segundo o art. 103 do Estatuto da Criança e do Adolescente (ECA), considera-se ato infracional a conduta descrita como crime ou contravenção penal ("Lei n. 8.069", 1990). O adolescente, por ser inimputável pela lei, não recebe pena, mas sim medida socioeducativa.

No campo do Direito, o ato infracional estaria no âmbito do Direito Infracional, o qual, de acordo com Rosa (2007), ganhou sua autonomia com a elaboração do ECA. No entanto, o autor ressalta que não se pode mais encarar a questão do ato infracional com base em uma ilusória concepção de Direito Penal Juvenil. Segundo ele:

Para que o Direito Infracional possa ser levado a sério, mostra-se necessária a fixação de um modelo de atuação. Não se trata de resgatar o falso e enfadonho dilema de construção de um Direito Penal Juvenil, proposta defendida por muitos sob o argumento de que a ausência de aplicação das normas de Direito Penal torna a atuação na seara infracional discricionária, sendo que somente o Direito Penal concederia a segurança jurídica almejada aos adolescentes (Rosa, 2007, p. 9).

Com essa distinção, o Direito Infracional demanda um sistema próprio, que afaste a pretensão de normatização desses adolescentes e que possa rever a atual concepção de medidas socioeducativas, originadas de uma perspectiva pedagógica cujo intuito é "reformar" subjetivamente esses sujeitos. Como nos 
disse Freud (2004), a pulsão não se educa, ainda mais a pulsão de morte. $\mathrm{Na}$ mesma direção freudiana, Rosa (2007) parece contrapor a visão normatizante do Direito em relação à questão do ato infracional, quando afirma:

A medida socioeducativa não pode pretender reeducar, nem deseducar, corrigir ou corromper, melhorar nem piorar o adolescente. Deve respeitar sua autonomia e somente impor restrições pessoais, atendido o devido processo legal. O que se pretende construir de fato [...] é uma atuação na área da Infância e Juventude, especialmente no ato infracional, que respeite o adolescente em sua singularidade e não se arvore, em nome da nazista pretensão pedagógica, na imposição de um modelo de conduta social, de normatização (p. 14-15).

A crítica de Rosa (2007) segue ainda na direção de uma leitura positiva do ato infracional, pois, segundo ele, uma transgressão como essa pode, diante da acomodação de diversos atores jurídicos, incomodar a tal ponto que se possa encarar a questão do ato infracional de frente e elaborar novos caminhos de atuação. Afinal, trata-se de uma enorme contradição: "uma sociedade que não promove as mínimas condições de sobrevivência dentro da legalidade e exige, ao mesmo tempo, o respeito à espoliação" (Rosa, 2007, p. 92). O autor igualmente critica a posição de querer se impor "um bem" ao adolescente envolvido com a prática do ato infracional, e defende a posição de que este seja reconhecido como sujeito de seu próprio desejo.

Por certo o desejo dos genitores e do próprio Poder Judiciário, por seus atores, irrompe no ato infracional, mormente querendo imaginariamente fazer o (seu) bem. Ao movimento do adolescente de se rebelar, de deixar de ser o objeto de desejo de seus pais, surge, não raro, a Instituição para realinhar o adolescente, então objetificado, ao desejo dos pais, ocasionando, muitas vezes, o agravamento subjetivo do adolescente e o desconsiderando como sujeito. [...] Os adultos, especialistas em adolescente, mesmo imaginariamente, acreditam saber que é bom para este, especificamente no tocante à normalização de seu desejo, mesmo que ao preço da autonomia do sujeito (Rosa, 2007, p. 2).

Rosa (2007), embora sendo do campo jurídico, aposta no inconsciente, tal como a psicanálise o faz. Para a psicanálise, cabe ao analista pôr o adolescente a falar de seu ato. $\mathrm{O}$ ato do sujeito não é sem sentido para ele. À psicanálise interessa as motivações inconscientes que permeiam esse ato. Tal como nos diz Barra (2005):

O trabalho comumente realizado com os sujeitos criminosos está referendado por uma visão patologizante em que a prática do delito é ora justificada por um distúrbio 
de conduta ou por uma personalidade psicopática, ora determinada pela ausência de condições sociais, políticas e econômicas que levariam o sujeito ao crime, como se não houvesse outro jeito. $\mathrm{O}$ que a psicanálise pode oferecer se verifica na consideração do estatuto subjetivo da conduta delituosa (p. 224).

Diferentemente do Direito, que, ao tomar o ato como um desvio, pretende enquadrar o adolescente a uma norma, a psicanálise dá um estatuto subjetivo ao ato infracional, reconhecendo seu valor de singularidade, o qual se expressa contra todo e qualquer ideal normativo pretendido em uma instituição como o CIAM.

Esses modos distintos de abordagem do problema decorrem da maneira como cada campo concebe a lei. Portanto, é de fundamental importância pensar a concepção da lei jurídica e da Lei simbólica, tal como a psicanálise a concebe, para tentar estabelecer a relação entre ambas. Essa diferenciação provoca um impasse, cuja presença se faz sentir diretamente na direção do tratamento institucional, particularmente quando o psicólogo que trabalha na instituição jurídica é orientado pela psicanálise.

Sabemos que qualquer instituição do âmbito jurídico, seja ela cárcere, delegacia, tribunal, etc., pretende, em maior ou menor escala, aplicar a lei jurídica para um sujeito. Essas instituições se integram cada vez mais com os aparelhos de uma sociedade normalizadora. Vê-se nelas uma imposição normativa aos seus usuários, onde a lei funciona como uma norma a ser seguida, tal como já discutimos anteriormente.

O impasse ocorre porque, do ponto de vista da psicanálise, há modalidades distintas de um sujeito elaborar seus interditos, que dependem da forma como se deu a transmissão da Lei para cada um e como esta se encontra dentro do sujeito. Uma lei só poderá interditar o ato de um sujeito se esta se fizer pela via do simbólico, pela via do significante, cujo registro não corresponde ao funcionamento normativo da instituição. Assim, vê-se um descompasso entre a aplicação da lei jurídica e a inscrição simbólica da Lei para cada sujeito. Como resolver tal impasse para que as leis possam operar?

Tomemos o que assinala Hoyer (2010), ao nos alertar: "Qualquer instituição - educativa, social ou psicológica - que considerar a norma como uma promessa capaz de extinguir o 'mal' estará visando obter um poder ilimitado sobre todos, isto é, a universalização do singular” (p. 106). Logo, uma instituição não poderá perder de vista que a lei não será significada por todos os sujeitos de uma mesma forma, ela sempre será singular para cada um. É preciso, portanto, que a singularidade prevaleça em detrimento da universalidade. 
Essa separação entre lei jurídica e Lei simbólica sugere inclusive outra distinção, remetida à questão do sujeito, a qual Lemerle (2004) nomeou como sujeito do direito e sujeito do desejo. A autora parte do princípio de que um sujeito é uma construção ligada ao desejo, e retoma a questão do complexo de Édipo e da função paterna como "o terceiro separador de uma criança e sua mãe, constitutivo de uma possibilidade para o ser humano de chegar a ser sujeito de seu desejo" (Lemerle, 2004, p. 8). Isto é, o desejo de um sujeito só poderá emergir mediante a operação do interdito do incesto possibilitado pela função paterna. É a operação da lei simbólica que pode possibilitar a constituição do sujeito do desejo.

Já o sujeito do direito está mais ligado às leis sociais e jurídicas criadas por uma sociedade. Nesse sentido, podemos afirmar que nos constituímos como sujeitos de direitos a partir do nosso nascimento e da nossa inserção na cultura, em que nos enquadramos às regras sociais e jurídicas, pois, tal como afirmou Lemerle (2004), "Carregamos conosco as fantasias de nossa linhagem, e as nossas, como também carregamos, desde antes de nosso nascimento, a sociedade dentro da qual iremos viver" (p. 8).

Não há como pensar o sujeito do desejo desarticulado do sujeito do direito. A questão é que, no caso das instituições jurídicas, percebe-se que o sujeito do direito é sempre visado, até porque geralmente os usuários destas instituiçôes ou tiveram algum de seus direitos violados, ou violaram direitos alheios. Nesse sentido, é sempre um desafio fazer emergir o sujeito do desejo, na tentativa de uma possível articulação entre ambos. Espera-se que um sujeito não seja apenas um depositário de direitos, e sim, um sujeito que comparece com seu desejo e se responsabiliza por ele.

Para Altoé (2004), não basta, no trabalho institucional com adolescentes, tomá-los apenas como sujeitos de direitos, mas também como sujeitos de desejo. A psicanálise, ao operar em instituições jurídicas, deve se nortear pela suposição do sujeito do inconsciente, trazendo, desse modo, uma nova forma de intervenção. Nesse sentido, tomar o sujeito do desejo como via de tratamento para o adolescente infrator é oferecer-lhe escuta para que emerja a palavra no lugar do ato, visto que, segundo Guerra (2010), "O que faz o sujeito precipitar-se como resposta em ato é justamente o evitamento da verdadeira resposta, do aparecimento do sujeito como desejante" (p. 102).

Simbolicamente, criamos as instituições normatizadoras das relações sociais, no entanto tais instituições não consideram nem a estrutura simbólica nem as leis que a regem ao aplicar as penas. Por isso surgem os impasses com a presença da psicanálise, que trata de modo diverso as transgressões 
a ela endereçadas, pois toma como ponto de partida a suposição do sujeito do inconsciente, do sujeito do desejo. A respeito da posição da psicanálise acerca da questão da lei nas instituições jurídicas, Guyomard (2007) afirma que:

A psicanálise não é normativa, e que, portanto, não está a serviço do poder, das instituições e das diferentes famílias, então ela relativiza as leis. Ela não estabelece como norma e como critério de cura a adaptação às leis de uma sociedade. Muito pelo contrário, podemos dizer que, se uma ciência mostrou que a adaptação às leis de uma sociedade era um sinal de doença, que sob aspectos, isso custava muito caro, essa ciência foi a psicanálise (p. 5).

Essa posição da psicanálise remete ao que já foi dito, de que a Lei a qual a psicanálise está referida é de outra ordem e não a que se refere à adaptação do sujeito às normas da sociedade em que vive.

Tomando as duas concepções de lei supostas neste trabalho, temos, de um lado, a psicanálise, propondo a Lei do Pai como aquela que constitui o sujeito como sujeito social, ordenado segundo as leis da linguagem e do grupo, e referido ao desejo; de outro lado, temos o direito que se apoia em uma lei jurídica na qual o sujeito é dito de direito. Trazendo esse contraponto para o CIAM, assistimos ali o adolescente ser frequentemente colocado no lugar de depositário de um direito, sem a suposição acerca de seu desejo quanto às normas a ele impostas, reservando-lhe o lugar de objeto de uma lei jurídica.

Para Lacan (1998a), "Por nossa posição de sujeito, sempre somos responsáveis" (p. 873), por isso, o adolescente não pode ser reduzido a um lugar de objeto no qual simploriamente se deposita uma norma. Para que possa assumir a responsabilidade pelo seu desejo, é preciso antes alcançar o estatuto de sujeito. Afinal, como falar em responsabilidade jurídica, quando se concebe que parte dos processos psíquicos é da ordem do inconsciente? Essa é uma questão de suma importância, pois, para a psicanálise, o adolescente é não sem a responsabilidade por seu ato infracional.

\section{Responsabilizar-se pela posição de sujeito}

De acordo com Morelli (2001), o conceito de responsabilidade é relativamente recente, pois surgiu no final do século XVIII, relacionado à política, referindo-se ao caráter dos governos constitucionais que agiam sob o controle dos cidadãos. Mais tarde, esse conceito passou a indicar "a 
possibilidade de o indivíduo prever os efeitos do próprio comportamento e de corrigi-lo fundamentado nessa previsão" (Morelli, 2001, p. 152). No campo jurídico, a responsabilidade civil é sempre objetiva e diz respeito à obrigação de reparar dano a outrem causado por ato ilícito ("Decreto-Lei n. 2.848”, 1940).

No entanto, a responsabilidade não apenas é um conceito jurídico, mas também um conceito ético. Se tomarmos o que Lacan (2008b) afirma em "O seminário, livro 11", "o estatuto do inconsciente [...] é ético" (p. 37), podemos relacionar a ética com a responsabilidade sobre o desejo. Assim, não se trata apenas de responder pelos nossos atos ou por nossos atos falhos, mas de deixar falar o inconsciente. Essa é a responsabilidade a que a psicanálise nos convoca, já que opera com base no conceito freudiano de inconsciente. Nesse sentido, a questão da responsabilidade é da ordem do sujeito do desejo, pois, como nos diz Lacan (2003), esperase que "o homem se faça reconhecer por seus semelhantes pelos atos cuja responsabilidade ele assume” (p. 127).

Aliada à noção de responsabilidade, surge a de imputabilidade. Para a lei jurídica, o sujeito adolescente é nomeado penalmente com base no significante "inimputável” e, para contemplar a responsabilidade do adolescente infrator pela medida socioeducativa, criou-se uma legislação específica (ECA e Sinase). Para a psicanálise, qualquer sujeito deve se responsabilizar por seus atos, e esse é um dos principais preceitos da "psicanálise do criminoso", tal como nos disse Lacan (2003):

\begin{abstract}
A psicanálise do criminoso tem seus limites que são exatamente aqueles que em que começa a ação policial, em cujo campo ela deve se recusar a entrar. Por isso é que não há de ser exercida sem punição, mesmo quando o delinquente, infantil, por exemplo, se beneficiar de uma certa proteção da lei. Mas é porque a verdade que ela busca é a verdade de um sujeito, precisamente, que ela não pode fazer outra coisa senão manter a ideia da responsabilidade, sem a qual a experiência humana não comporta nenhum progresso (p. 131).
\end{abstract}

Ou seja, "esta certa proteção da lei" que, em nossos termos, seria representada pelo ECA (1990), não poderia, no campo da psicanálise, proteger o adolescente de si mesmo, de seu próprio inconsciente, de seu próprio desejo. Desse modo, a psicanálise possibilitaria uma escuta na qual o sujeito não ficaria no lugar de alienado de si mesmo. Ao contrário de um tratamento objetivo, que vise a prescrever açôes educativas, Lacan aposta na escuta analítica que possa propiciar ao sujeito uma integração de sua verdadeira responsabilidade. 
Lacan (1998b) afirma ainda que o crime não pode ser concebido fora de sua referência sociológica, porém as mazelas sofridas pelo sujeito adolescente, ocasionadas pela exclusão social que o perpassa, não devem se sobrepor à necessidade de o adolescente se responsabilizar pela sua posição de sujeito frente a seu ato, ou seja, informar, por meio da construção de um saber, qual a significação subjetiva de seu ato e qual a sua implicação nele.

Quando Lacan (1998b) propôs a "irrealização do crime", estava, com isso, propondo que o crime não fosse tomado pela realidade do ato, mas sim com base em uma cena fantasmática. Com isso, a psicanálise não "desumaniza o criminoso", pois, ao tomá-lo como sujeito, ela considera a singularidade inscrita na fantasmática daquele que cometeu o ato. $\mathrm{O}$ que se diferencia de uma universalidade do ato infracional, que, sob o ângulo da coletividade, propõe aspectos exclusivamente sociais para este.

Tomando o dito de Lacan (1998b), de que "a responsabilidade, isto é, o castigo, é uma característica essencial da ideia do homem que prevalece numa dada sociedade" (p. 139), Morelli (2001) afirmou que imputar uma responsabilidade ao sujeito é castigá-lo, é sentenciá-lo por seu ato. Diz o autor:

O cumprimento de uma medida jurídica, o cumprimento de uma pena, de um castigo, só terá, de fato, algum valor para o homem da polis se houver assentimento subjetivo, se for a ele possível formular uma questão sobre a sua responsabilidade no ato. [...] A psicanálise nos aponta que a responsabilidade pode ser ou não uma questão para o sujeito em determinado momento, em determinado ato. E que, se o sujeito não colocar em questão a sua relação com o ato, não questionar a sua responsabilidade, ele não assentirá à punição, muito embora possa cumprir o castigo (p. 159).

Logo, o assentimento subjetivo ao qual Morelli (2001) faz referência está diretamente atrelado à questão da responsabilidade, se ao sujeito for possível formular uma questão que tenha efeitos subjetivos e impliquem em mudança subjetiva frente a seu ato.

De acordo com Carvalho (2002), esse assentimento implica em uma mudança de posição subjetiva diante de uma nova conjectura possibilitada por uma construção analítica que, inicialmente, apresenta-se a partir de uma fixação libidinal, mas que força o sujeito a uma nova resposta. Tal assentimento se dá no campo do inconsciente, diferentemente do consentimento, do ato de consentir, o qual se dá no campo da consciência. 


\section{Conclusão}

Que alcance para a medida socioeducativa, se não pela via da responsabilidade no campo do registro simbólico? Segundo Philippi (2002), "A teoria psicanalítica invoca uma dimensão da responsabilidade que ultrapassa os limites do arbítrio humano - determinantes do cumprimento dos deveres impostos pela lei e pelo direito aos seus sujeitos - e o intima a uma tradução possível do real” (p. 386).

Nesse cenário, cabe ao analista inserido em uma instituição jurídica convocar o adolescente a falar sobre seu ato infracional. Nesse sentido, é importante recuperar a sua participação nesse ato, a fim de tornar possível uma retificação subjetiva que o implique em seu ato.

Ou seja, a escuta possibilita uma compreensão do ato infracional como aquele que vem desvelar questóes da ordem do inconsciente, apostando na possibilidade de o sujeito assumir outra posição subjetiva, ao se apropriar de um saber advindo dele mesmo. Dessa forma, aposta-se que uma via possível para o alcance de uma medida socioeducativa é a via do simbólico, a via da responsabilidade.

Dentro desse contexto, faz-se necessário pensar como a Lei opera em cada sujeito individualmente. O que implica afirmar que o trabalho do psicanalista no âmbito jurídico deve apostar na apreensão da posição subjetiva do sujeito em relação à Lei simbólica instauradora do desejo, a partir da escuta das modalidades de exercícios das leis sociais desses adolescentes que se revelam por seus atos infracionais. Assim, a responsabilidade pelo ato transgressor, de acordo com a premissa da psicanálise, se dá pela via de um assentimento subjetivo, uma nova resposta do sujeito em relação ao seu ato.

\section{Referências}

Altoé, S. (2004). A psicanálise pode ser de algum interesse no trabalho institucional com crianças e adolescentes? In S. Altoé (Coord.). Sujeito do direito, sujeito do desejo: direito e psicanálise. (pp. 51-60). Rio de Janeiro: Revinter.

Barra, M. B. (2005). Possibilidades e limites da psicanálise em um ambulatório de adolescentes em conflito com a lei. In S. Altoé \& M. M. Lima (Orgs.). Psicanálise, clínica e instituição. (pp. 215-224). Rio de Janeiro: Rios Ambiciosos. 
Brasil (2007). Secretaria Especial dos Direitos Humanos. Sistema Nacional de Atendimento Socioeducativo. Brasília: Conanda.

Carvalho, F. Z. F. (2002). O fim da cadeia de razôes: Wittgenstein crítico de Freud. São Paulo: Annablume.

Decreto-Lei n. 2.848, de 07 de dezembro de 1940. (1940, 31 dezembro). Código Penal (7a. ed.). São Paulo: Saraiva.

Freud, S. (2004). Pulsão e destinos da pulsão. In S. Freud. Obras psicológicas de Sigmund Freud: escritos sobre a Psicologia do inconsciente. (L. A. Hanns, Trad., Vol. 1, pp. 133-173). Rio de Janeiro: Imago. [Texto original publicado em 1915]

Guerra, A. M. C. (2010). Quando um crime surpreende um sujeito: a psicanálise na política da defesa social. In A. M. C. Guerra \& J. O. Moreira (Orgs.). A psicanálise nas instituiçôes públicas. (pp. 91-106). Curitiba: CVR.

Guyomard, P. (2007). A Lei e as leis. In S. Altoé (Coord.). A Lei e as leis: direito e psicanálise. (pp. 1-59). Rio de Janeiro: Revinter.

Hoyer, C. (2010). A função paterna na instituição: do individual ao coletivo. Rio de Janeiro: Garamond.

Lacan, J. (1998a). A ciência e a verdade. In Escritos. (pp.869-892). Rio de Janeiro: Jorge Zahar. [Texto original publicado em 1966]

Lacan, J. (1998b). Introdução teórica às funções da psicanálise em criminologia. In Escritos. (pp. 127-151). Rio de Janeiro: Jorge Zahar. [Texto original publicado em 1950]

Lacan, J. (2003). Premissas a todo o desenvolvimento possível da criminologia. In Outros escritos. (pp.127-131). Rio de Janeiro: Jorge Zahar. [Texto original publicado em 1950]

Lacan, J. (2008a). O seminário, livro 7: a ética da psicanálise. Rio de Janeiro: Jorge Zahar. \{Seminário de 1959-1960\}.

Lacan, J. (2008b). O seminário, livro 11: os quatro conceitos fundamentais da psicanálise. Rio de Janeiro: Jorge Zahar. [Seminário de 1964].

Lei n. 8.069 de 13 de julho de 1990. (1990, 16 julho). Dispõe sobre o Estatuto da Criança e do Adolescente, e dá outras providências. Diário Oficial da União, Brasília. 
Lemerle, R. M. (2004). Sujeito do direito, sujeito do desejo. In S. Altoé (Coord.). Sujeito do direito, sujeito do desejo: direito e psicanálise. (pp. 1-14). Rio de Janeiro: Revinter.

Liberati, W. D. (2002). Adolescente e ato infracional: medida socioeducativa e pena? São Paulo: Juarez de Oliveira.

Morelli, A. (2001, novembro). Responsabilidade: medida do homem; questão para o sujeito. Revista Curinga. Minas Gerais: Escola Brasileira de Psicanálise, 17, 152-161.

Philippi, J. N. (2002). A Lei: uma abordagem a partir da leitura cruzada entre direito e psicanálise. Belo Horizonte: Del Rey.

Rosa, A. M. (2007). Introdução crítica ao ato infracional: princípios e garantias constitucionais. Rio de Janeiro: Editora Lumen Juris. 